This item was submitted to Loughborough's Research Repository by the author.

Items in Figshare are protected by copyright, with all rights reserved, unless otherwise indicated.

\title{
Impact of raw material, yarn and fabric parameters, and finishing on water vapor resistance
}

PLEASE CITE THE PUBLISHED VERSION

http://dx.doi.org/10.1177/0040517512471745

PUBLISHER

(c) SAGE Publications

VERSION

AM (Accepted Manuscript)

LICENCE

CC BY-NC-ND 4.0

\section{REPOSITORY RECORD}

Cubric, Ivana Salopek, Zenun Skenderi, and George Havenith. 2019. "Impact of Raw Material, Yarn and Fabric Parameters, and Finishing on Water Vapor Resistance". figshare. https://hdl.handle.net/2134/12733. 
This item was submitted to Loughborough's Institutional Repository (https://dspace.lboro.ac.uk/) by the author and is made available under the following Creative Commons Licence conditions.

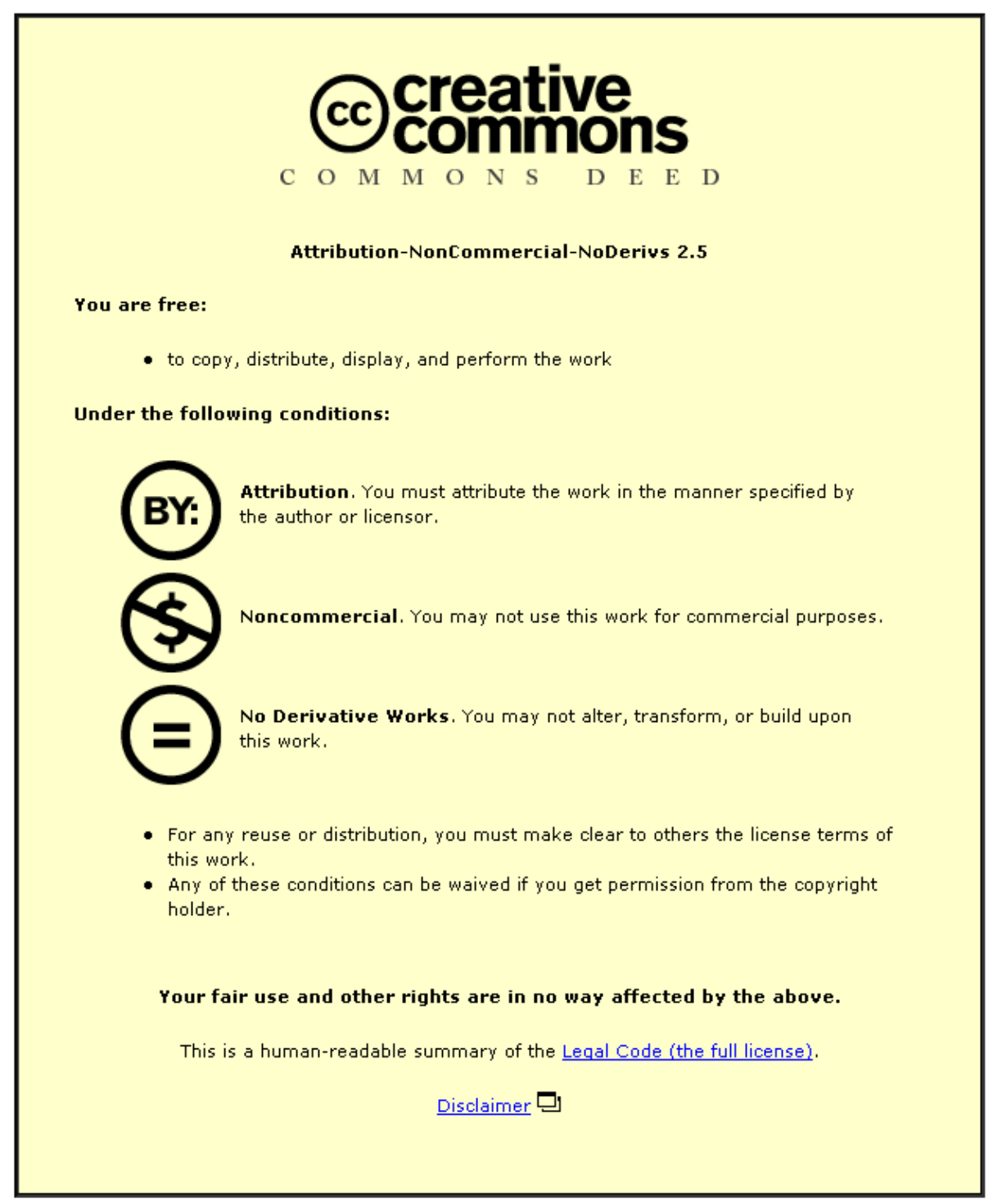

For the full text of this licence, please go to: http://creativecommons.org/licenses/by-nc-nd/2.5/ 


\title{
Impact of raw material, yarn and fabric parameters, and finishing on water vapor resistance
}

1. Ivana Salopek Cubric $1 \Uparrow$

2. Zenun Skenderi1

3. George Havenith2

1. 'Department of Textile Design and Management, University of Zagreb, Croatia

2. Environmental Ergonomics Research Centre, Loughborough University, Loughborough, $U K$

1. Ivana Salopek Cubric, Department of Textile Design and Management, University of Zagreb, Prilaz baruna Filipovica 28a, 10000 Zagreb, Croatia. Email: ivana.salopek@ttf.hr

doi: $10.1177 / 0040517512471745$

Textile Research Journal July 2013 vol. 83 no. 12 1215-1228

\section{Impact of raw material, yarn and fabric parameters and finishing on water vapor resistance}

\begin{abstract}
The objective of this study is to explore a number of technical-technological parameters affecting the water vapor resistance of knitted fabric and clothing, as well as to develop a predictive model that describes the prominent affecting parameters. Thirty-four knitted fabrics were carefully produced and measured on a sweating guarded hotplate and thermal manikin. The study focused on the influence of the following parameters on the transfer of water vapor: type of textile fibers, yarn and knitted fabric parameters, finishing of fabrics (recipes include bleaching, dyeing and softening) and body activity. The statistical analysis, performed to examine the relationship between observed parameters, indicated medium correlation between water vapor resistance and moisture regain $(\mathrm{R}=0.7)$. Furthermore, the
\end{abstract}


relationship between water vapor resistance and the following knitted fabric parameters is especially prominent: mass per unit area, knitted fabric thickness and tightness factor $(\mathrm{R}=0.9)$. When the fabrics are made into ensembles, however, effects of material differences become small and the differences between garments more difficult to discriminate; even more so when movement is present.

Keywords: water vapor resistance, sweating guarded hotplate, thermal manikin, knitted fabric

\section{Introduction}

Man is, concerning anatomy and organism physiology, predestined for life in moderate and hot climates. Under these conditions the body can maintain thermal equilibrium without additional interventions. But as soon as the ambient temperature drops well under $20^{\circ} \mathrm{C}$, the organism cannot maintain the body temperature for a longer period and in this case clothing takes the role of an additional thermoregulator ${ }^{1}$. The establishment of thermal equilibrium, in which man feels comfortable and needs minimal physiological adjustments, depends on a series of complex interactions among physiological, psychological, neurophysiological and physical factors which should be fulfilled to a certain extent.

The development of science and technology, as well as the improvement of social standards, shifted the requirements of textile customers who prefer garments that provide a satisfactory level of comfort to a higher level ${ }^{2}$. Nowadays many people are, due to the nature of their work, exposed to different atmospheric influences - from heat to cold and frequent weathering factors. Therefore, being able to wear a garment with appropriate protective properties as well as a satisfactory level of comfort is very important.

Clothing plays a very important role in maintaining the equilibrium of heat and moisture transfer and it is one of the essential goals for researchers to define mechanisms of their transfer and the parameters of relevance. According to Niwa's ${ }^{3}$ predictions of priorities for textile experts in the future, it is important to take into consideration human sensibility and start a "new textile engineering in which man plays an important role" during textile manufacturing.

Conclusions of previous investigations on textile properties carried out by physiologists ${ }^{4}$ are that raw material composition does not significantly affect comfort parameters and that 
subjects do not recognize the difference between garments made of different raw material compositions or fabrics of different structure. In contrast, investigations done by textile experts indicate that there are relevant differences in resistance to heat and water vapor transfer ${ }^{5}$ caused by such material differences.

In an earlier investigation, Oglakcioglu ${ }^{6}$ et al. compared knitted fabrics produced from cotton and angora fibres in different ratios. The analysis indicated that $25 \%$ of angora fiber caused significant difference in relative water vapor permeability values. Cil et al. ${ }^{7}$ investigated comfort-related properties of cotton and acrylic single jersey fabrics taking into account three variables: fiber composition, yarn count and fabric tightness. As far as the yarn count is concerned, the samples from fine yarn gave higher moisture vapor transfer values. Also, the slack fabrics features higher water transfer rates, as did the presence of acrylic fiber in the yarn composition. Sampath and Senthilkumar ${ }^{8}$ reported the improvement of water vapour transmission trough single jersey structures after moisture management finish for 15$20 \%$. In another investigation, Sampath et al. ${ }^{9}$ reported that untreated fabric made of spun polyester has higher water vapor resistance than the one made of cotton $\left(3.26 \mathrm{~m}^{2} \mathrm{~Pa} \mathrm{~W}^{-1} \mathrm{vs}\right.$. $\left.2.84 \mathrm{~m}^{2} \mathrm{~Pa} \mathrm{~W}^{-1}\right)$. After moisture management treatment, the decrease in water vapour resistance for polyester fabric is significant ( $R_{\text {et }}$ is $2.49 \mathrm{~m}^{2} \mathrm{~Pa} \mathrm{~W}^{-1}$ ), but not for cotton fabric ( $\mathrm{R}_{\text {et }}$ is $2.73 \mathrm{~m}^{2} \mathrm{~Pa} \mathrm{~W} \mathrm{~W}^{-1}$ ). Zhou et al. ${ }^{10}$ showed that, among the woollen knitted fabric plated with different yarns, the one plated with cotton yarn is the best at spreading liquid in the bottom surface and shows good moisture management properties. Chen et al. ${ }^{11}$ demonstrated that warp knitted fabrics with branching structure absorbed water faster than the corresponding interchanged plain knitted fabrics. The investigation of the relationship between different knitted structure and some thermo-physiological comfort parameters was also conducted by Yanilmaz and Kalaoglu ${ }^{12}$. They concluded that the water evaporation rate decreases with an increase of thickness due to increase of compactness and decrease of air space.

Understanding the way in which the multitude of yarn, fabric and clothing design parameters lead to optimally functioning clothing is important in order to be able to improve the currently available clothing. A vast number of studies looked at specific clothing properties and their relation to its performance. However in most of these studies, where e.g. man made fibers are compared to natural fibres ${ }^{13}$, or materials with different properties like the yarn structure ${ }^{14}$, or the fabric parameters ${ }^{15-17}$, the researchers did not manage to produce yarns/fabrics/clothing that was identical, differing only in one single factor. Hence outcomes could never be fully attributed to a single parameter. In most cases, off the shelve clothing is 
used, or prototypes are made from different fabrics with different weights, porosities etc. To the authors knowledge no studies have attempted to produce clothing where the whole process from raw material selection, yarn production via fabric production to the clothing production was controlled and thus where clothing was produced where a maximal number of characteristics can be independently analyzed. Therefore the present study aims to analyze the vapor resistance of knitted fabrics and garments made of yarns in which the production was maximally controlled in terms of selection of raw material, yarn properties, parameters of knitted fabric and finishing.

Our preliminary investigations of the parameters of the knitted fabric were performed on a smaller number of carefully designed knitted fabric samples. Concerning the fiber type, it was shown that using polyester with profiled cross-section reduces heat and water vapor transfer,

while it is the greatest in the samples of the knitted fabric made of viscose yarns ${ }^{18}$. Knitted fabrics, in which the elastane yarn in parallel with the main yarn was fed into each second course during knitting, have a considerably higher resistance to heat and water vapor transfer than the same structures without the elastane component ${ }^{19}$. Among the yarn parameters affecting mass transfer considerably, fineness and thickness are to be pointed out, while fabric modules (linear, surface and volume), tightness factor, mass per unit area and porosity belong to the most important knitted fabric parameters ${ }^{20,21}$.

For the purposes of the investigation presented in this paper, it was necessary to design garment samples made of the controlled fabrics discussed above and manufacture them under carefully controlled conditions.

\section{Experimental}

The present paper explores a number of technical-technological parameters affecting the water vapor resistance of knitted fabric and clothing worn next to the skin, and thereby the thermophysiological comfort of clothing. The parameters studied are: type of textile fibers, various yarn and knitted fabric parameters, influence of fabric finishing (comparison of raw and finished fabrics) and parameters of body activity. Figure 1 shows the production stages, i.e. how the fabrics and garments were produced with the goal of allowing parametric testing of the different properties. Each stage is explained in detail in the following sections.

\section{Yarn raw materials}


For the purposes of this study the following raw materials with different absorption properties were selected: $100 \%$ cotton, $50 / 50 \%$ cotton/modal, $100 \%$ viscose, $100 \%$ lyocell $\left(\right.$ Tencel $^{\circledR}$ ) and $100 \%$ polyester standard. From the named raw materials combed single yarns were produced. The yarns were made in four counts: 20,17, 14 and 12 tex for each raw material type. The average twist coefficient of produced yarns $\left(\alpha_{\text {tex }}\right)$ is 3417 .

\section{Knitting}

The mentioned yarns were used to make weft-knitted plain single jersey fabrics. The fabrics were knitted on the circular knitting machine Relanit E, gauge E28 with 48 knitting systems made by Mayer \& CIE. When designing the knitted fabric, the same course/cm $(20 \pm 0.5$ per $1 \mathrm{~cm}$ ) was defined for all knitted fabrics. Thus, the machine was adjusted in such a way that the manufacture of the knitted fabric with the mentioned density was possible.

\section{Finishing}

After relaxation (for a duration of 120 hours), a piece of each knitted fabric was cut off and prepared for testing as raw (unfinished) knitted fabric. The remaining samples were finished.

The finishing was performed in industrial conditions, according to the standard recipes that are used for the finishing of commercial knitwear in two knitting factories. Due to the fact that different raw materials are used, two recipes were defined. The first recipe was used for finishing of cotton, cotton/modal, viscose and lyocell fabrics. Those fabrics were bleached at $98^{\circ} \mathrm{C}$ for 60 minutes, dyed with dyestuff produced by Ciba (rinse for $10 \mathrm{~min}$ at $50^{\circ} \mathrm{C}$, neutralised for $10 \mathrm{~min}$ at $70^{\circ} \mathrm{C}$, soaped twice for $10 \mathrm{~min}$ at $95^{\circ} \mathrm{C}$, rinsed for $10 \mathrm{~min}$ at $70^{\circ} \mathrm{C}$ and rinsed for $10 \mathrm{~min}$ cold) and softened to ensure better sewability of knitted fabric. The second finishing recipe was used for finishing of polyester fabric only. This fabric was bleached at $80^{\circ} \mathrm{C}$ for 30 minutes, dyed on $130^{\circ} \mathrm{C}$ for 35 minutes and finally softened. Table 1 shows the raw material composition, the yarn count and the label of each fabric.

\section{Garment production}

Garment ensembles (T-shirt and shorts) were produced from the finished knitted fabrics made of $100 \%$ cotton, $50 / 50 \%$ cotton/modal, $100 \%$ viscose, $100 \%$ Tencel ${ }^{\circledR}$ and $100 \%$ polyester standard, all with the same count of 20 tex (i.e. from knitted fabrics designated as C20f, CM20f, V20f, T20f and PS20f). The construction of garments was made according to the body measures of a Newton manikin ${ }^{22}$. 


\section{Testing}

Within the scope of the experimental part, the following yarn properties were tested: count, twist level, yarn diameter, unevenness parameters, tensile properties, hairiness and coefficient of yarn friction.

The yarn count $(\mathrm{Tt})$ was determined by the use of skein method, as described in ISO $2060^{23}$. A torsiometer twist tester, produced by Mesdan lab, was used to measure the number of twists (Tm). The measurement was carried out using the untwist/retwist method, according to ISO $17202^{24}$. The yarn diameter (d) was measured from the yarn images obtained using an Olympus BX51 microscope equipped with camera. The parameters that characterize the yarn unevenness i.e. number of thin places (Ntn), number of thick places (Ntk), number of neps $(\mathrm{Ntn})$ and coefficient of mass variation $(\mathrm{CVm})$ were measured using the Keisokki evenness tester, model KET-80. During the measurement, the following sensibility levels were used: $50 \%$ for thin places, $+50 \%$ for thick places and $+200 \%$ for neps. Tensile properties of produced yarns, i.e. breaking force $(\mathrm{F})$ and breaking elongation $\left(\varepsilon_{\mathrm{B}}\right)$ were measured on a dynamometer Statimat M produced by Textechno, as described in ISO $2062^{25}$. The number of fibers in different lengths $(2,4,6$ and $8 \mathrm{~mm})$ was determined using the equipment produced by Zweigle company. The speed of yarn delivery was set to $50 \mathrm{~m} \mathrm{~min}^{-1}$. Finally, the coefficient of yarn friction ( $\mu$ ) was determined using the F-meter G 534 produced by Zweigle, according to the ASTM D 3108-0 $27^{26}$.

The following knitted fabric parameters were determined for all fabrics: stitch density (S), stitch length (l), thickness ( $\mathrm{t}$ ), mass per unit area (m), Munden constants ( $\left.\mathrm{k}_{\mathrm{c}}, \mathrm{k}_{\mathrm{w}}, \mathrm{k}_{\mathrm{s}}, \mathrm{R}\right)$, tightness factor (TF) and porosity $(\varepsilon)$. The stitch density was determined by multiplying the number of courses and wales per unit area, taking into account EN $14971^{27}$. The stitch length was determined as proposed in the EN $14970^{28}$. Knitted fabric thickness was experimentally determined using a thickness meter, with a pressure of $10 \mathrm{cN} \mathrm{cm}^{-2}$. The mass per unit area was determined by weighing a knitted fabric sample with an area of $1 \mathrm{dm}^{2}$ on an analytical scale. For the calculation of Munden constants $\left(\mathrm{k}_{\mathrm{c}}, \mathrm{k}_{\mathrm{w}}, \mathrm{k}_{\mathrm{s}}\right.$ and $\left.\mathrm{R}\right)$, tightness factor (TF) and porosity $(\varepsilon)$, the following equations were used ${ }^{29,30}$ :

$$
\begin{aligned}
& k_{c}=c \times l \\
& k_{w}=w \times l
\end{aligned}
$$




$$
\begin{aligned}
& k_{s}=S \times l^{2} \\
& R=k_{c} x k_{w}^{-1} \\
& T F=T t^{1 / 2} \times l^{-1} \\
& \varepsilon=1-\rho_{a} x \rho b^{-1}
\end{aligned}
$$

where $\mathrm{c}$ is the number of courses per unit length, 1 is the knitted stitch length, $w$ is the number of wales per unit length, $S$ is the stitch density, Tt is yarn count, $\rho_{a}$ is the fabric density and $\rho_{b}$ is the fiber density.

The air permeability of the samples was measured using the air permeability tester FX 3300 produced by Textest AG. The measurements were performed according to EN ISO $9237^{31}$, with constant pressure drop of $100 \mathrm{~Pa}$.

To test the water vapor resistance of knitted fabrics, a sweating guarded hotplate (Measurement Technology Northwest, Seattle, USA), model SGHP-8.2 was used. Tests were performed in accordance with ISO $11092^{32}$ - room condition $35^{\circ} \mathrm{C}, 40 \%$ relative humidity and air speed $1 \mathrm{~m} \mathrm{~s}^{-1}$. The temperature of test plate (i.e. "skin") was $35^{\circ} \mathrm{C}$.

Measurements of the water vapor resistance of garment ensembles were performed on thermal manikin Newton produced by Measurement Technology Northwest, Seattle, USA ${ }^{33}$. The manikin was equipped with a walking mechanism. For the purposes of testing the following movement speed was defined: 0 steps/min (static) and 18 double steps $/ \mathrm{min}$. Tests on the manikin were done under the same isothermic conditions as testing done using the sweating guarded hotplate; i.e. $35^{\circ} \mathrm{C}$ and $40 \%$ R.H.

The statistical analysis of obtained results was performed using the Statistica Release package, version 8.0. The following statistical methods were used: linear regression, multiple regression and Spearman's rank correlation test.

\section{Results}

The basic material test results for yarns and fabrics are presented in Table 2 and 3. The relation of the water vapor resistance of the fabrics to the basic yarn parameters, and the correlations amongst yarn parameters is given in Table 4 . 
The relation of the water vapor resistance to the knitted fabric parameters, and their correlations amongst each other are given in Table 6 . The summary of both regression statistics is given in the Tables 5 and 7.

Figure 2 shows the test results of the water vapor resistance measured on the sweating guarded hotplate, while Figure 3 additionally shows the test results of garment ensembles on the manikin in state of rest and motion.

Experimental uncertainty estimates, used to assess the confidence in the presented results are shown in the Table 8.

The results of knitted fabric air permeability are given on the Figure 4.

\section{Discussion}

\section{Impact of raw material composition}

The measured water vapor resistances of knitted fabrics are within the range $2.9-4.4 \mathrm{~m}^{2} \mathrm{~Pa} \mathrm{~W}^{-}$

${ }^{1}$ for raw fabrics, and 2.3-4.0 $\mathrm{m}^{2} \mathrm{~Pa} \mathrm{~W}^{-1}$ for finished fabrics (Figure 2). It is noticeable how the raw samples made of lyocell and viscose fibers (that have the highest moisture regain among the tested samples) on average have a considerably lower resistance to water vapor transfer than the samples made of the other tested raw materials. For example, the difference in the water vapor resistance of the unfinished samples made of cotton and viscose/lyocell fibers with a count of 17 tex (samples $\mathrm{C} 17 \mathrm{r}$ and V17r), amounts to 28\% (Fig. 2). Furthermore, the test of Spearman's ranks showed that the correlation between moisture regain and water vapor resistance of knitted fabrics is medium (the correlation coefficient obtained is $R=0.74$ ). These results show that both the raw material and the fiber type from which the knitted fabric were made, influence the the water vapor resistance to a certain extent.

\section{Impact of yarn parameters}

The differences in water vapor resistances of fabrics of the same raw material, but different counts, ranges from $8 \%$ (for knitted fabrics made of the blend of cotton/modal fibers; samples CM20r versus CM12r) to $27 \%$ (for the knitted fabrics made of cotton fibers; samples C20r versus $\mathrm{C} 12 \mathrm{r}$ ). The water vapor resistance decreases for fabrics made of finer yarns (for all observed raw materials), which is in agreement with findings presented by Cil et al. ${ }^{11}$. It is to be assumed that the important cause of the mentioned differences lies in changes in the yarn count and twist level which alters the stitch fullness with the yarn. Among the investigated 
yarns, the higher the yarn count is, the lower the number of twists is. If from investigated 17 yarns only those with the exact same count (for example, yarns V17r, T17r and CM17r, that have the same count of 16.8 tex and different number of twists: 806,851 and $870 \mathrm{~m}^{-1}$ ) are observed, the regularity of the increase of water vapor resistance with the increase of number of twists can be reported. The measured values of water vapor resistance for observed yarns in $\mathrm{m}^{2} \mathrm{~Pa} \mathrm{~W}^{-1}$ are: 3.07 (sample V17r), 3.33 (sample T17r) and 4.19 (sample CM17r). In view of the regression analysis carried out, it is concluded that the relationship between the water vapor resistance of the knitted fabric and the yarn parameters (yarn count, twist level, coefficient of mass variation and coefficient of friction) is medium $(\mathrm{R}=0.7)$. Water vapor resistance of the fabric correlates positively with yarn count and friction coefficient. It correlates negatively with number of twists and coefficient of mass variation. In the regression model, among all the variables, the variable of the yarn friction coefficient is statistically significant. The correlation between the mentioned variable and the water vapor resistance is positive and medium $(\mathrm{r}=0.78$; Table 4$)$. The correlation between the water vapor resistance and yarn count and number of twists is also medium $(r=0.59$ and $r=-0.59$ respectively, Table 4). In the multiple regression analysis, $50 \%$ of the variance of the water vapor resistance was explained by the mentioned yarn parameters (Table 5).

\section{Impact of knitted fabric parameters}

The analyzed weft-knitted single jersey fabrics are distinct in comparison to other textile materials because the proportion of holes in the knitted structure is significantly greater than in the case of other textile structure like weaves or non-wovens. As seen from the Table 3, all tighter structures have lower porosity which reduces the air permeability and directly affects the water vapor resistance. This observation is in accordance with data from Yanilmaz and Kalaoglu ${ }^{12}$. Table 7 shows that the relationship between the water vapor resistance and the fabric parameters (thickness, mass per unit area, stitch length, Munden constants, tightness factor and porosity) is very strong $(\mathrm{R}=0.9)$ with several high correlation values (Table 6). Water vapor resistance correlates positively with thickness, mass per unit area, stitch length and tightness factor and negatively with Munden constants and porosity. The correlation between the dependent variable (water vapor resistance) and thickness, mass per unit area and tightness factor is very strong. Medium correlation exists between the dependent variable and loop length, Munden constant $\mathrm{k}_{\mathrm{c}}$ and porosity. In a multiple regression analysis, the fabric 
parameters together were able to explain $91 \%$ of the variance in the water vapor resistance. The model of multiple linear regression for finished fabrics with the dependent variable of water vapor resistance $\left(R_{e t}\right)$ and independent variables of thickness $(t)$, mass per unit area (m), stitch length (1), Munden constants ( $\mathrm{k}_{\mathrm{c}}, \mathrm{k}_{\mathrm{w}}, \mathrm{k}_{\mathrm{s}}$ and $\left.\mathrm{R}\right)$, tightness factor (TF) and porosity $(\varepsilon)$ is:

$$
\begin{aligned}
& \mathrm{Ret}_{\mathrm{et}} /\left(\mathrm{m}^{2} \mathrm{PaW}^{-1}\right)=-7.4+7.87 \mathrm{t} / \mathrm{mm}+0.04 \mathrm{~m} /\left(\mathrm{g} \mathrm{m}^{-2}\right)-2.86 \mathrm{l} / \mathrm{mm}+2.36 \mathrm{k}_{\mathrm{c}}+4.48 \mathrm{k}_{\mathrm{w}} \\
& -0.86 \mathrm{k}_{\mathrm{s}}+0.85 \mathrm{R}-4.77 \mathrm{TF} /\left(\mathrm{tex}^{1 / 2} \mathrm{~mm}^{-1}\right)+4.10 \varepsilon
\end{aligned}
$$

As can be seen from the presented model, there is a significant correlation between the water vapor resistance and the knitted fabric parameters. The validation of the proposed model was additionally carried out on three cotton single jersey fabrics. The results of measured water vapor resistance for additionally measured fabrics differ up to $6 \%$ from the values obtained using the proposed model (fabric 1: Ret measured $=2.90 \mathrm{~m}^{2} \mathrm{~Pa} \mathrm{~W}^{-1}$, Ret calculated $=$ $3.08 \mathrm{~m}^{2} \mathrm{~Pa} \mathrm{~W}^{-1}$; fabric 2: Ret measured $=3.20 \mathrm{~m}^{2} \mathrm{~Pa} \mathrm{~W}^{-1}$, Ret calculated $=3.12 \mathrm{~m}^{2} \mathrm{~Pa} \mathrm{~W}^{-1}$; fabric 3 : $\left.R_{\text {et measured }}=4.02 \mathrm{~m}^{2} \mathrm{~Pa} \mathrm{~W}^{-1}, \mathrm{R}_{\text {et calculated }}=4.15 \mathrm{~m}^{2} \mathrm{~Pa} \mathrm{~W}^{-1}\right)$.

The obtained results of experimental uncertainty indicate that the highest contribution to the uncertainty of water vapor measurements came from the resolution of sample cutting equipment (value of standard uncertainty is 0.3 ; Table 8 ). The standard uncertainties of the rest of the sources indicated are within the limits proposed on the basis of inter-laboratory research. The positive outcome of the analysis was accomplished due to the fact that the protocol of the measurement included a number of activities intended to reduce the uncertainty in measurement. In order to minimize the uncertainties, the measuring instruments and all sensors used had been calibrated by authorized personnel prior to the measurements and all measurements were carried out by experienced and trained $\operatorname{staff}^{34}$. A number of additional good measurement practices proposed by the Guide of uncertainty in measurement ${ }^{35}$ were also taken before and during the measurement process. Based on these procedures, it is concluded that the obtained results of water vapor measurement, as well as the proposed model and concluding remarks, are reliable.

\section{Impact of finishing}

As can be seen in Figure 4, after the finishing process, the air permeability of all investigated fabrics decreased. The measured decrease of values is up to $20 \%$. The decrease of air 
permeability in knitted fabrics is due to the relaxation of fabrics that affected the loop shape and, at the same time, the size of holes within the loop. Figure 2 shows that finishing (according to the described recipes that include bleaching, dyeing and softening) reduces the water vapor resistance of all fabric samples. In relation to resistances of unfinished knitted fabrics, the water vapor resistance of the finished versions is lowered between $1 \%$ (sample $\mathrm{T} 12$ ) to $40 \%$ (sample $\mathrm{C} 14$ ), with a mean of $13 \%$. In comparison, changes in water vapor transmission trough single jersey structures reported by Sampath and Senthilkumar were around $15-20 \%{ }^{8}$. The reason for the mentioned reduction of resistance after finishing may be found in changes in the knitted fabric structure caused by the chemical processes performed. Namely, as can be seen from the results presented in Table 3, after finishing there were significant changes in the stitch density and a considerable reduction of the fabric thickness caused the reduction of the water vapor resistance. It becomes evident how changes in the water vapor resistance between unfinished and finished samples are significantly greater in the samples made of natural fibers and blends with natural fibers (a change by as much as $40 \%$ for the sample C14) than in the samples made of natural polymers (a change by as much as $-10 \%$ for the sample $\mathrm{T} 17)$. The above observation leads to the conclusion that the described finishing process is more suitable for the samples made of natural fibers. Namely, a reduction in the water vapor resistance under warm environmental conditions, in which it is necessary to facilitate the transfer of as much sweat as possible from the skin to the environment, positively affects an individual's perception of comfort. In the investigation reported by Sampath et al. ${ }^{9}$, the finishing treatment significantly affected the water vapor resistance of polyester, but not of cotton fabric. The results of this investigation showed the similar decrease of water vapor resistance for both cotton and polyester fabric, amounting to $15 \%$.

Considering the water vapor resistance of unfinished and finished samples, the following model of linear regression can be defined:

$$
R_{\text {et finished }}\left(\mathrm{m}^{2} \mathrm{PaW}^{-1}\right)=1.4602+0.4555 R_{\text {et unfinished }}\left(\mathrm{m}^{2} \mathrm{PaW}^{-1}\right)
$$

\section{Fabric differences versus ensemble differences}

Comparing the vapor resistance of the ensembles (Fig. 3) in static conditions to those of the fabrics, the results seem quite consistent. Apart from PS20f, which seems relatively higher as ensemble then as fabric, the other four fabrics have the same order of vapor resistance for 
fabric and ensemble. However in relative terms, differences in vapor resistance between different ensembles are much smaller than differences in vapor resistance between fabrics.

\section{Impact of movement}

The ranking observed in the static ensemble measurements on the manikin is quite similar to that in the dynamic (walking) tests. Differences in the raw material, which was used to make the knitwear ensemble, are still showing an effect on the vapor resistance. However, just like the differences within the static condition, the differences within the values concerning the knitted fabric raw material during walking are relatively small too, amounting to a maximum of 5\% (samples T20f and PS20f). Although the movement speed was relatively slow (18 steps/min), the recorded differences in the resistance of the knitted fabric in the state of rest and motion are significant, amounting to about $18 \%$.

In general, it seems that when measured as ensembles, so with the internal and external air layers included, any effects of raw material become minimal.

\section{Conclusion}

Quality characterization of the properties of thermophysiological comfort of textile products requires a systematic approach including measurements and calculations of a series of parameters along fiber - yarn - knitted fabric - finishing - garment. In the present study the whole process of garment production was controlled starting at the fiber level, in order to ensure that like for like comparisons could be made. In order to make particular conclusions with greater certainty, effects of parameters should be considered in groups, using samples of carefully designed properties.

The performed tests indicate that certain yarn and knitted fabric properties affect the knitted fabric water vapor resistance to a greater extent. The following yarn parameters are especially prominent: count, twist level and friction, while the following knitted fabric parameters are the most important: mass per unit area, knitted fabric thickness and tightness factor. It turned out that finishing affects the change of the water vapor resistance of the knitted fabric to a certain extent. The applied finishing treatment of the knitted fabric according to a commercial recipe reduces the water vapor resistance of the knitted fabric, and the structure of the knitted fabric itself becomes more stable. When the fabrics are made into ensembles, however, effects of material differences become small and the differences between garments more difficult to discriminate; even more so when movement is present. 
This is due to the strong contribution of the enclosed and surface air layers to the total values, which will be very similar over all garments given the identical design.

Optimal thermophysiological comfort of the knitted structure can be achieved if all parameters of the technological manufacturing and finishing processes have been chosen meticulously in accordance with the requirements determined by the application of the product.

\section{Acknowledgement}

The authors are sincerely grateful to the spinning mills Predilnica Litija from Litija, Slovenia and Predionica Klanjec (within the group Linz-Textil) from Klanjec, Croatia, for their contribution in the production of yarns. The research is supported by the Ministry of Science, Education and Sports, under the project 117-0000000-2984.

\section{References}

1. Havenith G. Heat balance when wearing protective clothing. Ann Ocup Hyg 1999; 43: 289296.

2. Wang L and Chuang L. A new method for measuing dynamic fabric heat and moisture comfort. Exp Therm Fluid Sci 2005; 29: 705-714.

3. Niwa M. The importance of clothing science and prospects for the future. Int $J$ Clo Sci Tech 2002; 14: 238-246.

4. Fanger P O. Thermal comfort - Analysis and applications in environmental engineering. New York: McGraw-Hill Book Company, 1972.

5. Hollies N R S, Custer A G, Morin C J and Howard M E. A human perception analysis approach to clothing comfort. Text Res $J$ 1979; 49: 557-654.

6. Oglakcioglu, N, Celik P, Bedez Ute T, Marmarali A and Kadoglu H. Thermal Comfort Properties of Angora Rabbit/Cotton Fiber Blended Knitted Fabrics. Text Res J 2009; 79, 10: 888-894. 
7. Cil MG, Nergis UB, Candan C. An Experimental Study of Some Comfort-related Properties of Cotton - Acrylic Knitted Fabrics. Text Res J 2009; 79, 10: 917-923.

8. Sampath MB, Senthilkumar M. Effect of Moisture Management Finish on Comfort Characteristics of Microdenier Polyester Knitted Fabrics. J Ind Text 2009; 39, 2: 163-173.

9. Sampath MB, Aruputharaj A, Senthilkumar M and Nalankilli G. Analysis of thermal comfort characteristics of moisture management finished knitted fabrics made from different yarns. J Ind Text 2012; 42, 1: 19-33.

10. Zhou L, Feng X, Du Y and Li Y. Characterization of Liquid Moisture Transport Performance of Wool Knitted Fabrics. Text Res J 2007; 77, 12: 951-956.

11. Chen Q, Fan J T, Sarkar MK. Biomimetics of branching structure in warp knitted fabrics to improve water transport properties for comfort. Text Res J 2012; 82, 11: 1131-1142

12. Yanılmaz M, Kalaoğlu F. Investigation of wicking, wetting and drying properties of acrylic knitted fabrics. Text Res $J$ 2012; 82, 8: 820-831

13. Kim J O and Spivak S M. Dynamic Moisture Vapor Transfer Trough Textiles - Part II: Further Techniques for Microclimate Moisture and Temperature Measurement. Text Res $J$ 1994; 64: 112-121.

14. Heus R and Kistemaker L. Thermal comfort of summer clothes for construction workers. In: Hodgdon JA, Heaney $\mathrm{JH}$ and Buono MJ (eds) Proceedings of 8th International Conference on Environmental Ergonomics. San Diego, 1998, pp. 273-276.

15. Tokura H, Jeong W S and Li X. The effect of clothing on thermoregulation and seasonal cold acclimation. In: Lotens W and Havenith G (eds) Proceedings of the Fifth International Conference on Environmental Ergonomics. Maastricht: TNO-Intstitute of Perception, 1992, pp. 216-217.

16. Bakkevig M, Volla T T and Sandsund M. Sweat transport in double-and single-layer underwear. In: From J, Ducharme M and Tikuisis P (eds) Proceedings of the Sixth International Conference on Environmental Ergonomics. Montebello: Defense and Civil Institute of Environmental Medicine, 1994, pp. 64-65.

17. Yasuda T, Miyama M and Yasuda H. Dynamic Water Vapor and Heat Transport Trough Layered Fabrics. Part II: Effect of Chemical Nature of Fibers. Text Res $J$ 1992: 62; 227-235. 18. Salopek I, Skenderi Z and Srdjak M. The heat and water vapor transfer of PES fabrics in comparison to fabrics from different raw material. In: Book of Proceedings of AUTEX 2008. Biella, Politechnico di Torino, 2008.

19. Mijović B, Salopek Čubrić I and Skenderi Z. Measurement of thermal parameters of skinfabric environment. Period Biol 2010; 112: 69-73. 
20. Skenderi Z, Salopek I and Srdjak M. The influence of yarn count to the transfer of heat and vapor through fabrics. In: Dragcevic Z (ed.) Proceedings of the $4^{\text {th }}$ International Textile, Clothing and Design Conference Magic World of Textiles. Dubrovnik: Faculty of Textile Technology, 2008, pp. 876-881.

21. Salopek I and Skenderi Z. Yarn and knitted fabric parameters that affect heat resistance. Melliand Int 2009; 15: 144-145.

22. Measurement Technology Northwest: Manikin Newton $-50^{\text {th }}$ Percentile Western Male, brochure

23. ISO 2060:1994 Textiles -- Yarn from packages -- Determination of linear density (mass per unit length) by the skein method

24. ISO 17202:2002 Textiles -- Determination of twist in single spun yarns -- Untwist/retwist method

25. ISO 2062:2009 Textiles -- Yarns from packages -- Determination of single-end breaking force and elongation at break using constant rate of extension (CRE) tester

26. ASTM D3108 - 07 Standard Test Method for Coefficient of Friction, Yarn to Solid Material

27. CSN EN 14971 - Textiles - Knitted fabrics - Determination of number of stitches per unit length and unit area

28. CSN EN 14970 - Textiles - Knitted fabrics - Determination of stitch length and yarn linear density in weft knitted fabrics

29. Spencer DJ. Knitting technology. Woodhead publishing limited, 2001.

30. Hsieh YL. Liquid transport in fabric structures. Text Res $J$ 1995; 65, 5: 299-307

31. ISO 9237:1995 Textiles -- Determination of the permeability of fabrics to air

32. ISO 11092:1993 Textiles -- Physiological effects -- Measurement of thermal and watervapour resistance under steady-state conditions (sweating guarded-hotplate test)

33. Havenith G, Richards M, Wang X, Brode P, Candas V, den Hartog E, Holmer I, Kuklane $\mathrm{K}$, Meinander $\mathrm{H}$ and Nocker W. Apparent latent heat of evaporation from clothing: attenuation and "heat pipe" effects. Appl Physiol 2008; 104, 142-149.

34. Salopek Cubric I, Skenderi Z, Mihelic-Bogdanic A and Andrassy M. Experimental study of thermal resistance of knitted fabrics. Exp Therm Fluid Sci 2012; 38, 223-228

35. ISO/IEC Guide 98:1993: Guide to the expression of uncertainty in measurement (GUM) 

Select raw materials with signifficantly different apsorption properties.

\section{RAW MATERIAL SELECTION}

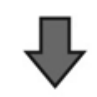

Maintain the same twist coefficient for all yarns (optimal for knitting). $\square$ YARN PRODUCTION

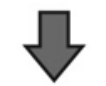

$\hookrightarrow$ FABRIC PRODUCTION

Maintain the horizontal density at 20 loops/cm.

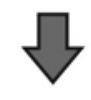

Select the optimal finishing recipe according to the product end/use.

FABRIC FINISHING

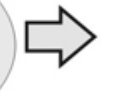

(

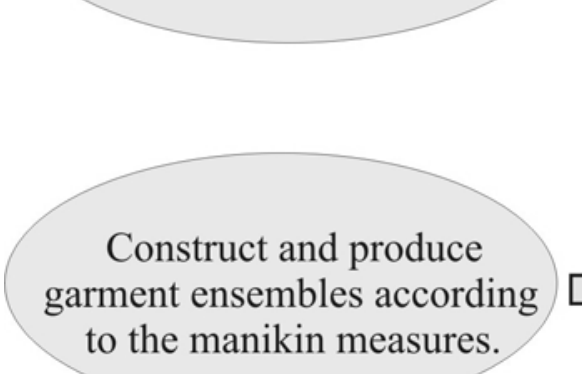

(1)

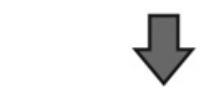

to the manikin measures.

GARMENT

PRODUCTION

Figure 1. Production stages of textile samples to be examined 


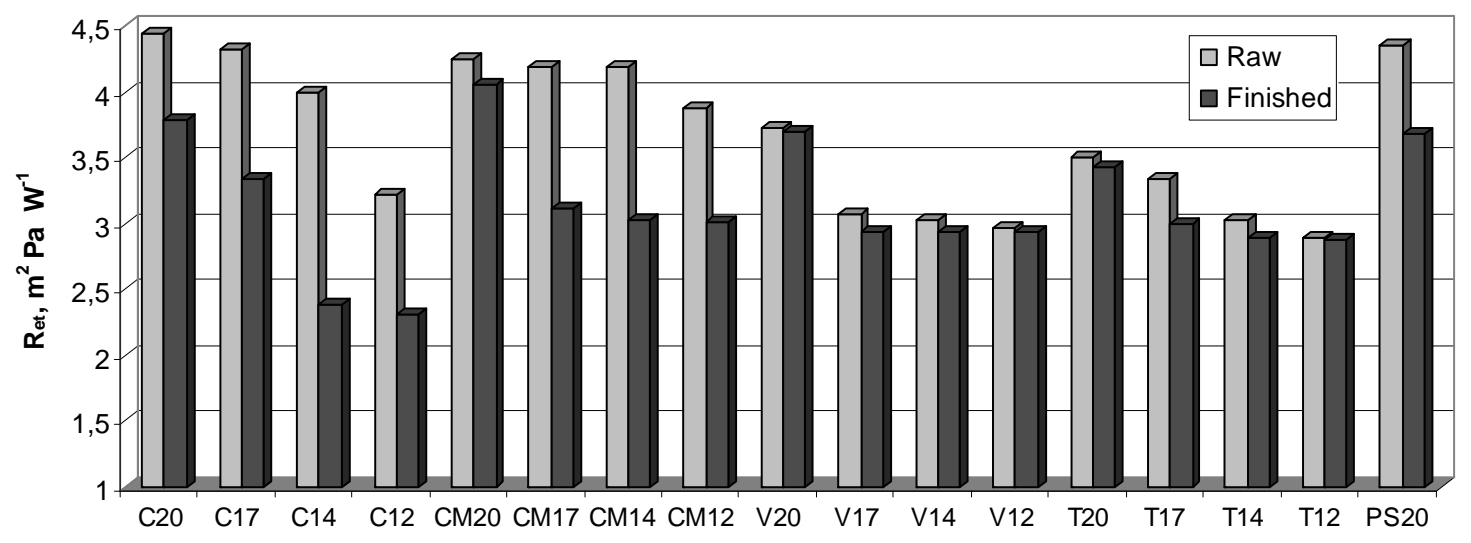

Figure 2. Knitted fabric water vapor resistance as measured on the skin model 


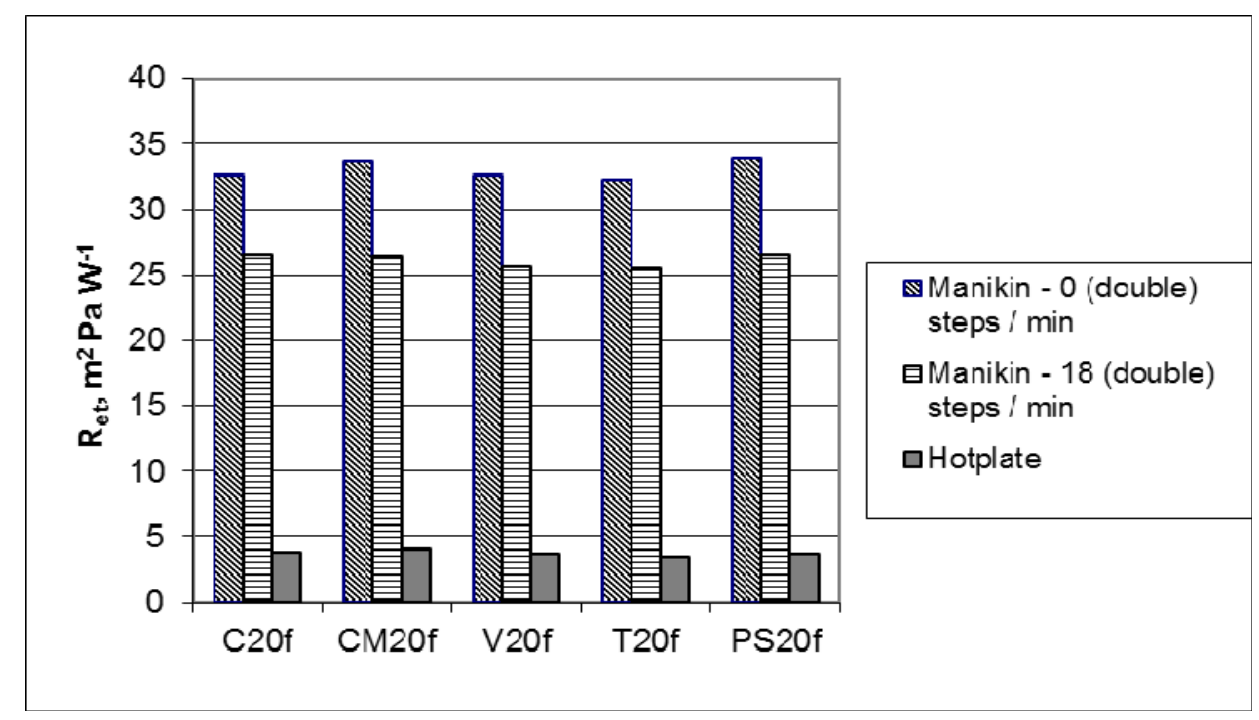

Figure 3. Knitted fabric and garment water vapor resistance as measured on the manikin (static and dynamic) and the sweating hotplate 


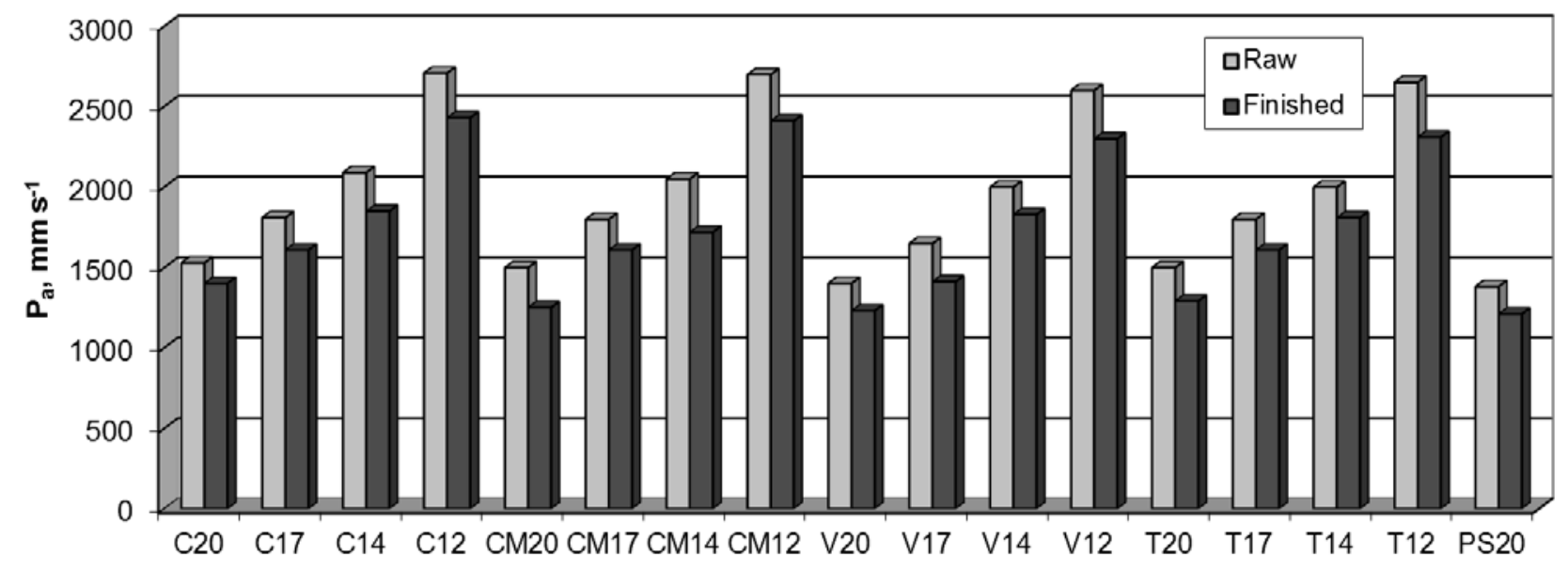

Figure 4. Knitted fabric air permeability 
Table 1. Overview of knitted fabric samples and their properties

\begin{tabular}{|c|c|c|c|c|}
\hline $\mathrm{Nr}$. & Raw material & Yarn count, tex & $\begin{array}{l}\text { Raw or } \\
\text { Finished }\end{array}$ & Designation \\
\hline 1 & $100 \%$ cotton & 20 & Raw & $\mathrm{C} 20 \mathrm{r}$ \\
\hline 2 & $100 \%$ cotton & 17 & Raw & $\mathrm{C} 17 \mathrm{r}$ \\
\hline 3 & $100 \%$ cotton & 14 & Raw & $\mathrm{C} 14 \mathrm{r}$ \\
\hline 4 & $100 \%$ cotton & 12 & Raw & $\mathrm{C} 12 \mathrm{r}$ \\
\hline 5 & $50 / 50 \%$ cotton $/$ modal & 20 & Raw & CM20r \\
\hline 6 & $50 / 50 \%$ cotton/modal & 17 & Raw & $\mathrm{CM} 17 \mathrm{r}$ \\
\hline 7 & $50 / 50 \%$ cotton/modal & 14 & Raw & CM14r \\
\hline 8 & $50 / 50 \%$ cotton $/$ modal & 12 & Raw & CM12r \\
\hline 9 & $100 \%$ viscose & 20 & Raw & V20r \\
\hline 10 & $100 \%$ viscose & 17 & Raw & V17r \\
\hline 11 & $100 \%$ viscose & 14 & Raw & V14r \\
\hline 12 & $100 \%$ viscose & 12 & Raw & $\mathrm{V} 12 \mathrm{r}$ \\
\hline 13 & $100 \%$ lyocell $\left(\right.$ Tencel $\left.^{\circledR}\right)$ & 20 & Raw & T20r \\
\hline 14 & $100 \%$ lyocell $\left(\right.$ Tencel $\left.^{\circledR}\right)$ & 17 & Raw & $\mathrm{T} 17 \mathrm{r}$ \\
\hline 15 & $100 \%$ lyocell $\left(\right.$ Tencel $\left.^{\circledR}\right)$ & 14 & Raw & $\mathrm{T} 14 \mathrm{r}$ \\
\hline 16 & $100 \%$ lyocell $\left(\right.$ Tencel $\left.^{\mathbb{R}}\right)$ & 12 & Raw & $\mathrm{T} 12 \mathrm{r}$ \\
\hline 17 & $100 \%$ polyester & 20 & Raw & PS20r \\
\hline 18 & $100 \%$ cotton & 20 & Finished & $\mathrm{C} 20 \mathrm{f}$ \\
\hline 19 & $100 \%$ cotton & 17 & Finished & $\mathrm{C} 17 \mathrm{f}$ \\
\hline 20 & $100 \%$ cotton & 14 & Finished & $\mathrm{C} 14 \mathrm{f}$ \\
\hline 21 & $100 \%$ cotton & 12 & Finished & $\mathrm{C} 12 \mathrm{f}$ \\
\hline 22 & $50 / 50 \%$ cotton $/$ modal & 20 & Finished & CM20f \\
\hline 23 & $50 / 50 \%$ cotton $/$ modal & 17 & Finished & CM17f \\
\hline 24 & $50 / 50 \%$ cotton $/$ modal & 14 & Finished & CM14f \\
\hline 25 & $50 / 50 \%$ cotton $/$ modal & 12 & Finished & CM12f \\
\hline 26 & $100 \%$ viscose & 20 & Finished & V20f \\
\hline 27 & $100 \%$ viscose & 17 & Finished & V17f \\
\hline 28 & $100 \%$ viscose & 14 & Finished & V14f \\
\hline 29 & $100 \%$ viscose & 12 & Finished & V12f \\
\hline 30 & $100 \%$ lyocell $\left(\right.$ Tencel $\left.^{\circledR}\right)$ & 20 & Finished & T20f \\
\hline 31 & $100 \%$ lyocell $\left(\right.$ Tencel $\left.^{\circledR}\right)$ & 17 & Finished & $\mathrm{T} 17 \mathrm{f}$ \\
\hline 32 & $100 \%$ lyocell $\left(\right.$ Tencel $\left.^{\circledR}\right)$ & 14 & Finished & T14f \\
\hline 33 & $100 \%$ lyocell $\left(\right.$ Tencel $\left.^{\circledR}\right)$ & 12 & Finished & $\mathrm{T} 12 \mathrm{f}$ \\
\hline 34 & $100 \%$ polyester & 20 & Finished & PS20f \\
\hline esignatio & $\begin{array}{l}\text { - cotton, CM - cotton } / \mathrm{mo} \\
\text { - raw, }- \text { - finished }\end{array}$ & & & 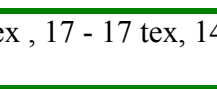 \\
\hline
\end{tabular}


Table 2. Test results of the yarn parameters

\begin{tabular}{|c|c|c|c|c|c|c|c|c|c|c|c|c|c|c|}
\hline $\begin{array}{l}\text { Designat } \\
\text { ion }\end{array}$ & $\mathrm{Tt}$, tex & $\begin{array}{l}\text { Tm, } \\
\mathrm{m}^{-1}\end{array}$ & $\begin{array}{l}\mathrm{d}, \\
\mathrm{mm}\end{array}$ & Ntn & Ntk & $\mathrm{Nn}$ & $\begin{array}{l}\text { CVm, } \\
\%\end{array}$ & $\begin{array}{l}\mathrm{F} \\
\mathrm{cN}\end{array}$ & $\begin{array}{l}\varepsilon_{\mathrm{B}} \\
\%\end{array}$ & $\mathrm{n}_{1}$ & $\mathrm{n}_{2}$ & $\begin{array}{r}\mathrm{n} \\
3\end{array}$ & $\begin{array}{l}\mathrm{n} \\
4\end{array}$ & $\mu$ \\
\hline $\mathrm{C} 20 \mathrm{r}$ & 19.9 & 742 & 0.18 & 0 & 13 & 15 & 11,5 & 292.9 & 5.6 & 52 & 20 & 1 & 1 & 0.15 \\
\hline $\mathrm{C} 17 \mathrm{r}$ & 16.9 & 842 & 0.16 & 0 & 10 & 18 & 11.2 & 245.5 & 4.9 & 50 & 16 & 1 & 1 & 0.14 \\
\hline $\mathrm{C} 14 \mathrm{r}$ & 14.3 & 935 & 0.15 & 0 & 23 & 10 & 12.6 & 205.5 & 4.5 & 32 & 8 & 0 & 1 & 0.14 \\
\hline $\mathrm{C} 12 \mathrm{r}$ & 12.1 & 966 & 0.14 & 0 & 27 & 25 & 14.1 & 220.8 & 4.7 & 30 & 8 & 1 & 0 & 0.13 \\
\hline CM20r & 19.9 & 801 & 0.18 & 0 & 8 & 15 & 11.1 & 401.6 & 5.2 & 45 & 6 & 0 & 0 & 0.19 \\
\hline CM17r & 16.8 & 870 & 0.17 & 0 & 10 & 38 & 12.3 & 227.8 & 4.5 & 38 & 4 & 0 & 0 & 0.14 \\
\hline CM14r & 14.4 & 952 & 0.15 & 0 & 35 & 118 & 13.3 & 203.9 & 4.9 & 37 & 4 & 0 & 0 & 0.14 \\
\hline CM12r & 12.2 & 976 & 0.14 & 0 & 60 & 100 & 14.2 & 158.3 & 4.7 & 32 & 6 & 1 & 0 & 0.15 \\
\hline V20r & 19.8 & 802 & 0.18 & 0 & 13 & 30 & 12.3 & 417.2 & 13.3 & 35 & 6 & 0 & 0 & 0.15 \\
\hline $\mathrm{V} 17 \mathrm{r}$ & 16.8 & 806 & 0.17 & 0 & 3 & 38 & 11.6 & 360.7 & 13.7 & 37 & 5 & 0 & 0 & 0.14 \\
\hline V14r & 14.4 & 910 & 0.15 & 0 & 3 & 35 & 12.1 & 298.4 & 12.1 & 34 & 6 & 0 & 0 & 0.13 \\
\hline V12r & 12.2 & 950 & 0.14 & 0 & 20 & 20 & 13.1 & 180.2 & 9.5 & 26 & 3 & 0 & 0 & 0.12 \\
\hline T20r & 20.1 & 770 & 0.18 & 0 & 3 & 18 & 10.8 & 713.4 & 9.8 & 60 & 22 & 1 & 1 & 0.13 \\
\hline $\mathrm{T} 17 \mathrm{r}$ & 16.8 & 851 & 0.17 & 0 & 0 & 23 & 11.2 & 550.5 & 9.1 & 46 & 9 & 0 & 0 & 0.15 \\
\hline $\mathrm{T} 14 \mathrm{r}$ & 14.4 & 915 & 0.15 & 0 & 8 & 48 & 12.4 & 368.8 & 7.7 & 49 & 16 & 0 & 1 & 0.13 \\
\hline $\mathrm{T} 12 \mathrm{r}$ & 12.1 & 970 & 0.14 & 0 & 10 & 42 & 13.8 & 295.9 & 7.6 & 27 & 6 & 0 & 0 & 0.10 \\
\hline PS20r & 20.0 & 684 & 0.20 & 0 & 0 & 0 & 5.9 & 363.0 & 11.9 & 32 & 5 & 0 & 0 & 0.18 \\
\hline
\end{tabular}

Legend: Tt - yarn count, Tm - number of twists per 1 meter, $\mathrm{d}$ - yarn diameter, Ntn - number of thin places on $1000 \mathrm{~m}, \mathrm{Ntk}$ - number of thick places on $1000 \mathrm{~m}$, Nn - number of neps on $1000 \mathrm{~m}, \mathrm{CVm}$ - coefficient of mass variation, $\mathrm{F}$ - breaking force, $\varepsilon_{\mathrm{B}}$ - breaking elongation, $\mathrm{n}_{1}$ - number of fibers of length $2 \mathrm{~mm}, \mathrm{n}_{2}$ - number of fibers of length $4 \mathrm{~mm}, \mathrm{n}_{3}$ - number of fibers of length $6 \mathrm{~mm}, \mathrm{n}_{4}$ - number of fibers of length $8 \mathrm{~mm}, \mu$ - mean value of friction coefficient 
Table 3. Test results of the knitted fabric parameters

\begin{tabular}{|c|c|c|c|c|c|c|c|c|c|c|}
\hline Designation & $\underset{\mathrm{cm}^{-2}}{\mathrm{~S}}$ & $\begin{array}{c}1 . \\
\mathrm{mm}\end{array}$ & $\underset{\mathrm{mm}}{\mathrm{t}}$ & $\begin{array}{c}\mathrm{m} . \\
\mathrm{g} \mathrm{m}^{-2}\end{array}$ & $\mathrm{k}_{\mathrm{c}}$ & $\mathrm{k}_{\mathrm{w}}$ & $\mathrm{k}_{\mathrm{s}}$ & $\mathrm{R}$ & $\begin{array}{c}\mathrm{TF}, \\
\text { tex }^{1 / 2} \\
\mathrm{~mm}^{-1}\end{array}$ & $\varepsilon$ \\
\hline $\mathrm{C} 20 \mathrm{r}$ & 225 & 2.91 & 0.46 & 142.78 & 5.2 & 3.6 & 19.1 & 1.4 & 1.54 & 0.82 \\
\hline $\mathrm{C} 17 \mathrm{r}$ & 247 & 2.85 & 0.44 & 123.44 & 5.4 & 3.7 & 20.1 & 1.5 & 1.45 & 0.83 \\
\hline $\mathrm{C} 14 \mathrm{r}$ & 263 & 2.75 & 0.38 & 100.10 & 5.4 & 3.7 & 19.9 & 1.4 & 1.36 & 0.84 \\
\hline $\mathrm{C} 12 \mathrm{r}$ & 300 & 2.70 & 0.36 & 91.00 & 5.4 & 4.1 & 21.9 & 1.3 & 1.28 & 0.85 \\
\hline CM20r & 237 & 2.70 & 0.46 & 141.01 & 5.1 & 3.4 & 17.3 & 1.5 & 1.66 & 0.80 \\
\hline CM17r & 243 & 2.60 & 0.44 & 121.11 & 5.1 & 3.3 & 16.5 & 1.6 & 1.59 & 0.82 \\
\hline CM14r & 273 & 2.60 & 0.42 & 107.77 & 5.1 & 3.6 & 18.5 & 1.4 & 1.44 & 0.83 \\
\hline CM12r & 300 & 2.55 & 0.39 & 94.30 & 5.1 & 3.8 & 19.5 & 1.3 & 1.36 & 0.84 \\
\hline V20r & 247 & 2.65 & 0.43 & 141.67 & 5.0 & 3.4 & 17.3 & 1.5 & 1.69 & 0.76 \\
\hline V17r & 253 & 2.50 & 0.38 & 121.50 & 4.9 & 3.3 & 15.8 & 1.5 & 1.65 & 0.79 \\
\hline V14r & 263 & 2.49 & 0.37 & 105.80 & 4.9 & 3.4 & 16.5 & 1.4 & 1.50 & 0.80 \\
\hline V12r & 310 & 2.48 & 0.34 & 95.82 & 5.0 & 3.9 & 19.4 & 1.3 & 1.39 & 0.81 \\
\hline T20r & 253 & 2.82 & 0.47 & 139.18 & 5.5 & 3.7 & 20.2 & 1.5 & 1.59 & 0.81 \\
\hline $\mathrm{T} 17 \mathrm{r}$ & 260 & 2.65 & 0.43 & 112.81 & 5.3 & 3.4 & 18.3 & 1.5 & 1.59 & 0.83 \\
\hline $\mathrm{T} 14 \mathrm{r}$ & 260 & 2.65 & 0.40 & 102.54 & 5.3 & 3.4 & 18.3 & 1.5 & 1.41 & 0.83 \\
\hline $\mathrm{T} 12 \mathrm{r}$ & 300 & 2.50 & 0.37 & 91.58 & 5.0 & 3.8 & 18.8 & 1.3 & 1.39 & 0.84 \\
\hline PS20r & 237 & 2.65 & 0.42 & 137.61 & 5.0 & 3.3 & 16.7 & 1.5 & 1.69 & 0.76 \\
\hline $\mathrm{C} 20 \mathrm{f}$ & 248 & 2.80 & 0.43 & 148.10 & 4.5 & 4.3 & 19.4 & 1.0 & 1.60 & 0.78 \\
\hline $\mathrm{C} 17 \mathrm{f}$ & 272 & 2.75 & 0.38 & 127.54 & 4.7 & 4.4 & 20.6 & 1.1 & 1.50 & 0.77 \\
\hline $\mathrm{C} 14 \mathrm{f}$ & 279 & 2.70 & 0.32 & 109.94 & 4.9 & 4.2 & 20.3 & 1.2 & 1.39 & 0.77 \\
\hline $\mathrm{C} 12 \mathrm{f}$ & 332 & 2.50 & 0.30 & 92.45 & 4.8 & 4.4 & 20.8 & 1.1 & 1.39 & 0.80 \\
\hline CM20f & 288 & 2.60 & 0.42 & 150.44 & 4.7 & 4.2 & 19.5 & 1.1 & 1.72 & 0.76 \\
\hline CM17f & 288 & 2.50 & 0.38 & 127.71 & 4.5 & 4.0 & 18.0 & 1.1 & 1.65 & 0.78 \\
\hline CM14f & 288 & 2.50 & 0.34 & 108.01 & 4.5 & 4.0 & 18.0 & 1.1 & 1.50 & 0.79 \\
\hline CM12f & 332 & 2.30 & 0.32 & 95.44 & 4.4 & 4.0 & 17.6 & 1.1 & 1.50 & 0.84 \\
\hline V20f & 286 & 2.55 & 0.40 & 150.20 & 4.7 & 4.0 & 18.6 & 1.2 & 1.75 & 0.75 \\
\hline V17f & 304 & 2.45 & 0.36 & 131.10 & 4.7 & 3.9 & 18.2 & 1.2 & 1.68 & 0.76 \\
\hline V14f & 323 & 2.40 & 0.34 & 111.80 & 4.6 & 4.1 & 18.6 & 1.1 & 1.56 & 0.77 \\
\hline V12f & 341 & 2.40 & 0.32 & 104.75 & 4.7 & 4.2 & 19.7 & 1.1 & 1.44 & 0.80 \\
\hline T20f & 272 & 2.70 & 0.40 & 150.18 & 4.6 & 4.3 & 19.8 & 1.1 & 1.66 & 0.74 \\
\hline $\mathrm{T} 17 \mathrm{f}$ & 280 & 2.60 & 0.35 & 128.08 & 4.4 & 4.3 & 19.0 & 1.0 & 1.59 & 0.76 \\
\hline T14f & 297 & 2.55 & 0.31 & 112.03 & 4.6 & 4.2 & 19.3 & 1.1 & 1.47 & 0.76 \\
\hline $\mathrm{T} 12 \mathrm{f}$ & 323 & 2.40 & 0.28 & 94.61 & 4.6 & 4.1 & 18.6 & 1.1 & 1.44 & 0.84 \\
\hline PS20f & 263 & 2.55 & 0.38 & 149.38 & 4.3 & 4.0 & 17.1 & 1.1 & 1.75 & 0.78 \\
\hline Min value & 225 & 2.40 & 0.38 & 142.78 & 4.3 & 3.3 & 16.5 & 1.0 & 1.54 & 0.78 \\
\hline Max value & 263 & 2.91 & 0.46 & 149.38 & 5.4 & 4.3 & 21.9 & 1.6 & 1.75 & 0.82 \\
\hline
\end{tabular}

Legend: $\mathrm{S}$ - stitch density, 1 - stitch length, $\mathrm{t}$ - fabric thickness, $\mathrm{m}$ - mass per unit area, $\mathrm{k}_{\mathrm{c}}, \mathrm{k}_{\mathrm{w}}, \mathrm{k}_{\mathrm{s}}, \mathrm{R}$ Munden constants, TF - tightness factor, $\varepsilon$ - fabric porosity 
Table 4. Correlation matrix of the water vapor resistance and yarn parameters

\begin{tabular}{c|ccccc}
\hline & $\mathrm{Tt}$ & $\mathrm{Tm}$ & $\mathrm{CVm}$ & $\mu$ & $\mathrm{R}_{\mathrm{et}}$ \\
\hline $\mathrm{Tt}$ & 1.00 & -0.94 & -0.67 & 0.68 & 0.59 \\
$\mathrm{Tm}$ & -0.94 & 1.00 & 0.75 & -0.71 & -0.59 \\
$\mathrm{CVm}$ & -0.67 & 0.75 & 1.00 & -0.49 & -0.32 \\
$\mu$ & 0.68 & -0.71 & -0.49 & 1.00 & 0.78 \\
$\mathrm{R}_{\mathrm{et}}$ & 0.59 & -0.59 & -0.32 & 0.78 & 1.00 \\
\hline
\end{tabular}


Table 5. Summary of the stepwise regression statistics for the prediction of water vapor resistance from yarn parameters

\begin{tabular}{|c|c|c|c|c|c|c|c|}
\hline & & Beta & Std.Err. of Beta & $\mathrm{B}$ & Std.Err. of B & $\mathrm{t}$ & p-level \\
\hline \multirow{5}{*}{$\begin{array}{l}\text { Step } 0: \mathrm{R}=0.71 \\
\mathrm{R}^{2}=0.51 \\
\text { Adj. } \mathrm{R}^{2}=0.34 \\
\mathrm{~F}=3.08 \\
\text { Std. Err. }=0.46\end{array}$} & Intercept & & & -3.43 & 6.34 & -0.54 & 0.60 \\
\hline & $\mathrm{Tt}$ & 0.68 & 0.81 & 0.12 & 0.14 & 0.84 & 0.42 \\
\hline & $\mathrm{Tm}$ & 0.58 & 1.04 & 0.01 & 0.01 & 0.56 & 0.59 \\
\hline & $\mathrm{CVm}$ & -0.06 & 0.51 & -0.02 & 0.15 & -0.11 & 0.92 \\
\hline & $\mu$ & 0.56 & 0.29 & 15.38 & 8.03 & 1.92 & 0.08 \\
\hline \multirow{4}{*}{$\begin{array}{l}\text { Step } 1: \mathrm{R}=0.71 ; \\
\mathrm{R}^{2}=0.51 ; \text { Adj. } \mathrm{R}^{2}=0.39 ; \mathrm{F}= \\
4.45 ; \\
\text { Std. Err. }=0.44\end{array}$} & Intercept & & & -3.02 & 4.91 & -0.62 & 0.55 \\
\hline & $\mathrm{Tt}$ & 0.63 & 0.61 & 0.11 & 0.11 & 1.03 & 0.32 \\
\hline & $\mathrm{Tm}$ & 0.49 & 0.59 & 0.03 & 0.01 & 0.83 & 0.42 \\
\hline & $\mu$ & 0.58 & 0.26 & 15.75 & 7.03 & 2.24 & 0.04 \\
\hline \multirow{3}{*}{$\begin{array}{l}\text { Step 2: } \mathrm{R}=0.69 ; \\
\mathrm{R}^{2}=0.48 ; \text { Adj. } \mathrm{R}^{2}=0.41 ; \mathrm{F}= \\
\text { 6.48; Std. Err. }=0.44\end{array}$} & Intercept & & & 0.98 & 0.76 & 1.29 & 0.22 \\
\hline & $\mathrm{Tt}$ & 0.17 & 0.25 & 0.03 & 0.05 & 0.67 & 0.51 \\
\hline & $\mu$ & 0.57 & 0.25 & 15.60 & 6.94 & 2.25 & 0.04 \\
\hline \multirow{2}{*}{$\begin{array}{l}\text { Step 3: } \mathrm{R}=0.68 ; \\
\mathrm{R}^{2}=0.46 ; \text { Adj. } \mathrm{R}^{2}=0.43 ; \mathrm{F}= \\
\text { 12.98; Std. Err. }=0.43\end{array}$} & Intercept & & & 1.03 & 0.74 & 1.39 & 0.19 \\
\hline & $\mu$ & 0.68 & 0.19 & 18.63 & 5.17 & 3.60 & 0.01 \\
\hline
\end{tabular}


Table 6. Correlation matrix of water vapor resistance and knitted fabric parameters

\begin{tabular}{c|cccccccccc} 
& $\mathrm{t}$ & $\mathrm{m}$ & $\mathrm{1}$ & $\mathrm{k}_{\mathrm{c}}$ & $\mathrm{k}_{\mathrm{w}}$ & $\mathrm{k}_{\mathrm{s}}$ & $\mathrm{R}$ & $\mathrm{TF}$ & $\varepsilon$ & $\mathrm{R}_{\mathrm{et}}$ \\
\hline $\mathrm{t}$ & 1.00 & 0.92 & 0.58 & -0.20 & -0.01 & -0.09 & -0.14 & 0.80 & -0.58 & 0.86 \\
$\mathrm{~m}$ & 0.92 & 1.00 & 0.60 & -0.19 & -0.02 & -0.11 & -0.04 & 0.88 & -0.72 & 0.84 \\
1 & 0.58 & 0.60 & 1.00 & 0.18 & 0.59 & 0.53 & -0.20 & 0.16 & -0.60 & 0.36 \\
$\mathrm{k}_{\mathrm{c}}$ & -0.20 & -0.19 & 0.18 & 1.00 & 0.31 & 0.74 & 0.58 & -0.38 & 0.20 & -0.37 \\
$\mathrm{k}_{\mathrm{w}}$ & -0.01 & -0.02 & 0.59 & 0.31 & 1.00 & 0.87 & -0.48 & -0.40 & -0.17 & -0.09 \\
$\mathrm{k}_{\mathrm{s}}$ & -0.09 & -0.11 & 0.53 & 0.74 & 0.87 & 1.00 & -0.03 & -0.48 & -0.24 & -0.26 \\
$\mathrm{R}$ & -0.14 & -0.04 & -0.20 & 0.58 & -0.48 & -0.03 & 1.00 & 0.06 & -0.16 & -0.21 \\
$\mathrm{TF}$ & 0.80 & 0.88 & 0.16 & -0.38 & -0.40 & -0.48 & 0.06 & 1.00 & -0.53 & 0.80 \\
$\varepsilon$ & -0.58 & -0.72 & -0.60 & -0.20 & -0.17 & -0.24 & -0.16 & -0.53 & 1.00 & -0.34 \\
$\mathrm{R}_{\mathrm{et}}$ & 0.86 & 0.84 & 0.36 & -0.37 & -0.09 & -0.26 & -0.21 & 0.80 & -0.34 & 1.00
\end{tabular}


Table 7. Summary of the stepwise regression statistics for the water vapor resistance and knitted fabric parameters

\begin{tabular}{|c|c|c|c|c|c|c|c|}
\hline & & Beta & $\begin{array}{l}\text { Std.Err. of } \\
\text { Beta }\end{array}$ & $\mathrm{B}$ & Std.Err. of B & $\mathrm{t}$ & p-level \\
\hline \multirow{10}{*}{$\begin{array}{c}\text { Step 0: } \mathrm{R}=0.95 ; \mathrm{R}^{2} \\
=0.91 ; \\
\text { Adj. } \mathrm{R}^{2}=0.78 ; \\
\mathrm{F}=7.45 ; \\
\text { Std. Err. }=0.22\end{array}$} & Intercept & & & -7.40 & 12.78 & -0.58 & 0.58 \\
\hline & $\mathrm{t}$ & 0.72 & 0.48 & 7.87 & 5.21 & 1.50 & 0.17 \\
\hline & $\mathrm{m}$ & 1.90 & 0.90 & 0.04 & 0.02 & 2.12 & 0.07 \\
\hline & 1 & 0.83 & 0.48 & -2.86 & 1.66 & -1.71 & 0.12 \\
\hline & $\mathrm{kc}$ & 0.77 & 0.95 & 2.36 & 2.91 & 0.80 & 0.44 \\
\hline & $\mathrm{kw}$ & 1.47 & 1.49 & 4.48 & 4.55 & 0.98 & 0.35 \\
\hline & ks & -1.92 & 2.06 & -0.86 & 0.92 & -0.93 & 0.38 \\
\hline & $\mathrm{R}$ & 0.10 & 0.36 & 0.85 & 3.07 & 0.27 & 0.78 \\
\hline & TF & -1.23 & 0.93 & -4.77 & 3.63 & -1.31 & 0.23 \\
\hline & $\varepsilon$ & 0.24 & 0.25 & 4.10 & 4.22 & 0.97 & 0.36 \\
\hline \multirow{9}{*}{$\begin{array}{c}\text { Step 1: } \mathrm{R}=0.95 \\
\mathrm{R}^{2}=0.91 \\
\text { Adj. } \mathrm{R}^{2}=0.81 \\
\mathrm{~F}=9.46 \\
\text { Std. Err. }=0.21\end{array}$} & Intercept & & & -6.23 & 11.35 & -0.55 & 0.60 \\
\hline & $\mathrm{t}$ & 0.63 & 0.35 & 7.00 & 3.92 & 1.78 & 0.11 \\
\hline & $\mathrm{m}$ & 1.89 & 0.84 & 0.04 & 0.01 & 2.24 & 0.05 \\
\hline & 1 & -0.77 & 0.42 & -2.68 & 1.44 & -1.85 & 0.10 \\
\hline & $\mathrm{kc}$ & 0.76 & 0.89 & 2.33 & 2.74 & 0.85 & 0.41 \\
\hline & $\mathrm{kw}$ & 1.26 & 1.22 & 3.86 & 3.72 & 1.03 & 0.32 \\
\hline & ks & -1.73 & 1.83 & -0.77 & 0.81 & -0.94 & 0.37 \\
\hline & TF & -1.14 & 0.83 & -4.42 & 3.21 & -1.37 & 0.20 \\
\hline & $\varepsilon$ & 0.25 & 0.22 & 4.38 & 3.85 & 1.13 & 0.28 \\
\hline \multirow{8}{*}{$\begin{array}{c}\text { Step 2: } R=0.95 ; R^{2} \\
=0.90 ; \\
\text { Adj. } R^{2}=0.82 ; \\
F=11.05 ; \\
\text { Std. Err. }=0.20\end{array}$} & Intercept & & & 1.12 & 7.23 & 0.15 & 0.87 \\
\hline & $\mathrm{t}$ & 0.48 & 0.30 & 5.36 & 3.37 & 1.59 & 0.14 \\
\hline & $\mathrm{m}$ & 1.70 & 0.80 & 0.03 & 0.01 & 2.13 & 0.06 \\
\hline & 1 & -0.66 & 0.39 & -2.28 & 1.34 & -1.69 & 0.12 \\
\hline & $\mathrm{kw}$ & 0.24 & 0.24 & 0.76 & 0.75 & 1.00 & 0.34 \\
\hline & ks & -0.19 & 0.28 & -0.08 & 0.12 & -0.67 & 0.51 \\
\hline & $\mathrm{TF}$ & -0.79 & 0.70 & -3.06 & 2.74 & -1.11 & 0.29 \\
\hline & $\varepsilon$ & 0.34 & 0.20 & 5.79 & 3.42 & 1.69 & 0.12 \\
\hline \multirow{7}{*}{$\begin{array}{c}\text { Step 3: } \mathrm{R}=0.94 ; \mathrm{R}^{2} \\
=0.89 ; \\
\text { Adj. } \mathrm{R}^{2}=0.83 ; \\
\mathrm{F}=13.54 ; \\
\text { Std. Err. }=0.20\end{array}$} & Intercept & & & -1.29 & 6.11 & -0.21 & 0.83 \\
\hline & $\mathrm{t}$ & 0.44 & 0.29 & 4.90 & 3.20 & 1.52 & 0.15 \\
\hline & $\mathrm{m}$ & 1.60 & 0.76 & 0.03 & 0.01 & 2.09 & 0.06 \\
\hline & 1 & -0.59 & 0.36 & -2.05 & 1.26 & -1.61 & 0.13 \\
\hline & $\mathrm{kw}$ & 0.13 & 0.16 & 0.39 & 0.51 & 0.76 & 0.46 \\
\hline & TF & -0.59 & 0.62 & -2.29 & 2.42 & -0.94 & 0.36 \\
\hline & $\varepsilon$ & 0.41 & 0.16 & 7.02 & 2.83 & 2.47 & 0.03 \\
\hline \multirow{6}{*}{$\begin{array}{c}\text { Step 4: } \mathrm{R}=0.94 ; \mathrm{R}^{2} \\
=0.88 ; \text { Adj. } \mathrm{R}^{2}= \\
0.83 ; \mathrm{F}=16.76 ; \\
\text { Std. Err. }=0.19\end{array}$} & Intercept & & & 0.79 & 5.37 & 0.14 & 0.88 \\
\hline & $\mathrm{t}$ & 0.44 & 0.28 & 4.84 & 3.14 & 1.53 & 0.15 \\
\hline & $\mathrm{m}$ & 1.72 & 0.73 & 0.03 & 0.01 & 2.34 & 0.03 \\
\hline & 1 & -0.56 & 0.35 & -1.94 & 1.23 & -1.57 & 0.14 \\
\hline & $\mathrm{TF}$ & -0.75 & 0.58 & -2.91 & 2.24 & -1.29 & 0.22 \\
\hline & $\varepsilon$ & 0.41 & 0.16 & 6.93 & 2.78 & 2.49 & 0.02 \\
\hline \multirow{5}{*}{$\begin{array}{c}\text { Step 5: } \mathrm{R}=0.93 ; \mathrm{R}^{2} \\
\quad=0.87 ; \text { Adj. } \mathrm{R}^{2}= \\
0.82 ; \mathrm{F}=19.44 ; \\
\text { Std. Err. }=0.20\end{array}$} & Intercept & & & -5.08 & 2.95 & -1.71 & 0.11 \\
\hline & $\mathrm{t}$ & 0.38 & 0.29 & 4.21 & 3.19 & 1.31 & 0.21 \\
\hline & $\mathrm{m}$ & 0.86 & 0.33 & 0.01 & 0.01 & 2.60 & 0.02 \\
\hline & 1 & -0.13 & 0.14 & -0.46 & 0.48 & -0.95 & 0.35 \\
\hline & $\varepsilon$ & 0.42 & 0.16 & 7.10 & 2.85 & 2.48 & 0.02 \\
\hline \multirow{4}{*}{$\begin{array}{c}\text { Step 6: } \mathrm{R}=0.93 ; \mathrm{R}^{2} \\
=0.86 ; \text { Adj. } \mathrm{R}^{2}= \\
\text { 0.82; } \mathrm{F}=25.79 ; \\
\text { Std. Err. }=0.20\end{array}$} & Intercept & & & -6.81 & 2.32 & -2.93 & 0.01 \\
\hline & $\mathrm{t}$ & 0.32 & 0.28 & 3.58 & 3.11 & 1.15 & 0.27 \\
\hline & $\mathrm{m}$ & 0.87 & 0.33 & 0.01 & 0.01 & 2.65 & 0.01 \\
\hline & $\varepsilon$ & 0.47 & 0.15 & 8.05 & 2.66 & 3.02 & 0.01 \\
\hline \multirow{3}{*}{$\begin{array}{c}\text { Step 7: R=0.9; } \mathrm{R}^{2} \\
=0.84 ; \text { Adj. } \mathrm{R}^{2}= \\
0.82 ; \mathrm{F}=37.17 ; \\
\text { Std. Err. }=0.20\end{array}$} & Intercept & & & -7.18 & 2.32 & -3.08 & 0.01 \\
\hline & $\mathrm{m}$ & 1.21 & 0.15 & 0.02 & 0.01 & 7.99 & 0.01 \\
\hline & $\varepsilon$ & 0.53 & 0.15 & 8.95 & 2.570 & 3.47 & 0.01 \\
\hline
\end{tabular}


Table 8. Results of uncertainty analysis of water vapour measurements on sweating guarded hotplate

\begin{tabular}{|c|c|c|c|c|}
\hline $\begin{array}{l}\text { Standard } \\
\text { uncertainty } \\
\text { component }\end{array}$ & Source of uncertainty & $\begin{array}{l}\text { Value of } \\
\text { standard } \\
\text { uncertainty }\end{array}$ & $\begin{array}{l}\text { Combined } \\
\text { standard } \\
\text { uncertainty }\end{array}$ & $\begin{array}{l}\text { Expanded } \\
\text { uncertainty }\end{array}$ \\
\hline $\mathrm{u}\left(\mathrm{Ret}_{\mathrm{et}}\right)$ & $\begin{array}{l}\text { Water vapor resistance } \\
\text { measurement, } \mathrm{m}^{2} \mathrm{~Pa} \mathrm{~W}{ }^{-1}\end{array}$ & 0.02057 & \multirow{2}{*}{0.02057} & \multirow{2}{*}{0.04114} \\
\hline $\mathrm{u}\left(\mathrm{R}_{\mathrm{etr}}\right)$ & $\begin{array}{l}\text { Repeatability from the previous } \\
\text { measurements }\end{array}$ & 0.00008 & & \\
\hline $\mathrm{u}\left(\mathrm{T}_{\mathrm{c}}\right)$ & Chamber temperature, ${ }^{\circ} \mathrm{C}$ & 0.012 & \multirow{3}{*}{0.032} & \multirow{3}{*}{0.064} \\
\hline $\mathrm{u}\left(\mathrm{T}_{\mathrm{tp}}\right)$ & Test plate temperature, ${ }^{\circ} \mathrm{C}$ & 0.003 & & \\
\hline $\mathrm{u}(\mathrm{Ts})$ & $\begin{array}{l}\text { Temperature sensor calibration, } \\
{ }^{\circ} \mathrm{C}\end{array}$ & 0.03 & & \\
\hline $\mathrm{u}(\mathrm{va})$ & Air velocity, $\mathrm{ms}^{-1}$ & 0.002 & \multirow[b]{2}{*}{0.003} & \multirow[b]{2}{*}{0.006} \\
\hline $\mathrm{u}(\mathrm{vs})$ & $\begin{array}{l}\text { Air velocity sensor calibration, } \\
\mathrm{ms}^{-1}\end{array}$ & 0.002 & & \\
\hline $\mathrm{u}(\mathrm{rc})$ & $\begin{array}{l}\text { Resolution of sample cutting } \\
\text { equipment, mm }\end{array}$ & 0.3 & & \\
\hline
\end{tabular}

